\title{
The growing role of web-based geospatial technology in disaster response and support
}

\section{Citation}

Akiyuki Kawasaki, Merrick Lex Berman and Wendy Guan. The growing role of web-based geospatial technology in disaster response and support. Disasters, 37(2). doi: 10.1111/ j.1467-7717.2012.01302.x

\section{Published Version}

doi:10.1111/j.1467-7717.2012.01302.x

\section{Permanent link}

http://nrs.harvard.edu/urn-3:HUL.InstRepos:27010008

\section{Terms of Use}

This article was downloaded from Harvard University's DASH repository, and is made available under the terms and conditions applicable to Other Posted Material, as set forth at http:// nrs.harvard.edu/urn-3:HUL.InstRepos:dash.current.terms-of-use\#LAA

\section{Share Your Story}

The Harvard community has made this article openly available.

Please share how this access benefits you. Submit a story.

\section{Accessibility}




\section{Introduction}

The Japanese earthquake and tsunamis on March 11, 2011 have provided a powerful reminder of nature's destructive force. Northeastern Japan, an area known for striking vistas, sheer cliffs, deep inlets, and narrow river valleys, has become the center of an unfolding global tragedy. Powerful tsunamis rushed inland, sweeping whole villages out to sea and leaving many thousands dead or missing. The sheer degree of wreckage left as the waves receded once again highlights, as in other disasters, the need for tools to aid in response and relief efforts. In this current and in other crises, the ability to synthesize information from multiple sources and to make available up-to-date maps and location information is of critical importance in ensuring a timely and effective response. Broader use of geospatial technologies—including Geographic Information System (GIS), Remote Sensing, and Global Positioning System (GPS) — provide the key for doing so in the future.

The conventional geospatial response to disasters has professional geospatial groups -from governmental agencies, relief response organizations, and GIS vendors - provide support to decision-makers on the ground. Most responses have featured the creation of centralized emergency operation centers in the damaged areas. These centers collect damage information, create and print out decision-support maps, and disseminate information in a top-down manner (Cova 1999 ; Kawasaki and Sadohara, 2005 ; Radke et al., 2000 ; Thomas et al., 2002 ; Yoshitomi 2004). In short, conventional geospatial responses have focused on relatively small, centralized teams that grapple with a vast amount of information. The recent development of web mapping technology, however, has led to a more dynamic, transparent, and decentralized disaster response, one that includes individuals and organizations from both inside and outside the damaged area. This movement started to emerge in the response to 
the Chuetsu earthquake in 2004 (Sawada et al., 2005), and was developed in response to Hurricane Katrina and other subsequent disasters (Curtis et al., 2006; Google 2006). And the Haiti earthquake in January 2010 as well as the Japan earthquake and tsunami in March 2011 demonstrated a much broader potential of geospatial technologies for use in disaster response-support.

As such, a technological transformation is underway that is changing the ways in which disaster relief is conducted. A number of studies have outlined the ways in which emerging interactive information technologies such as wiki, Twitter, and blogs have played important roles in disaster response-support (Mills et al., 2009; Underwood, 2010; Zook et al., 2010). This paper, however, takes a different route, and focuses on how web-based geospatial technological development has changed approaches to disaster response and relief efforts. It demonstrates the growing role of geospatial technologies and shows how such technologies have made possible broader, more focused cooperation in disaster relief-support. To this end, this paper first reviews how geospatial technologies have historically been used in major disasters. It marks Hurricane Katrina in 2005 as an important turning point for web-based geospatial development. The paper then uses case studies from Harvard University's geospatial portal project to show how the utilization of the technology changed since 2005 . The following section describes examples in which GIS was heavily utilized for supporting disaster response activities. We examine the change in available dataset types and geospatial disaster response-supporters, and then investigate the impact of geospatial technological changes on disaster relief effort in order to determine which factors of the technological developments affect disaster response-support. Finally, the paper discusses lessons learned from recent responses. In all, we hope this paper serves as a foundation for policymakers, relief response organizations, and GIS vendors 
to make better use of geospatial technologies to support disaster response and relief.

\section{The growing role of geospatial technologies}

\section{Use before Hurricane Katrina in 2005}

Since the late 1980s, a growing number of groups-from governmental organizations to academic associations, and private and public GIS groups - have made use of geospatial technologies to support responses to many U.S. disasters (Johnson, 1992; Cova, 1999; Radke et al., 2000). By the mid-1990s, information and data regarding hazards became available on the web (Radke et al., 2000), and during the 1994 Northridge earthquake individual damage information of buildings and housing were managed using GIS. The South Florida Water Management District was among the first groups to recognize the importance of an integrated GIS database for use in emergency response support. It developed a comprehensive critical facility GIS database that held crucial geographic and infrastructural data such as shelters, hospitals, and fire stations for the district (Householder, 1999).

Japan followed suit, beginning research on geospatial technologies to support disaster management in the early 1990s (Katayama, 1991; Meguro et al., 1999). During the Hokkaido earthquake of 1993, relevant authorities detected damaged areas using aerial photographs taken shortly after the quake (Saito et al., 2009). In the 1995 Kobe earthquake damage information was collected over a broad area using middle-resolution optical satellite and SAR satellite (Matsuoka and Yamazaki, 2001; Matsuoka et al., 2001), as high-resolution satellites were not available at that time. Analysts and response groups also made damage assessments through a broad use of aerial television images (Mitsutomi et al., 2002). Although no GIS basemap in Kobe existed when the earthquake occurred, detailed 
building damage was inspected and surveyed over a short period covering 7 cities and stored as GIS database by district unit. However, data sharing was limited and only a few authorized organizations and researchers were allowed access to the data.

In the immediate aftermath of the World Trade Center Terrorist attacks in New York City on September 11, 2001, geospatial technologies such as satellite and aerial imagery, LIDAR (Light Detection and Ranging) imagery, and hand-held electronic devices that combined GPS, Internet, and GIS databases were used for comprehensive support of emergency rescue and recovery operations (Thomas et al., 2002; Yoshitomi, 2004; National Research Council, 2007). This was one of the first major events in which remote sensing imagery of the immediate aftermath was utilized for multiple purposes on the day of the event. SPOT sensor acquired satellite coverage of Ground Zero and images were posted on the web, and the next day IKONOS satellite images were posted on the web and published in newspapers around the world (Huych and Adams, 2002). Aerial photographs and LIDAR imagery also aided search and rescue efforts. However, lower resolution satellite imagery such as Landsat TM, ERS and MODIS were not useful given the localized scale of events (Huych and Adams, 2002), and the pre- and post-processing times for remote sensing images might have negated their use in immediate response activities (Cutter, 2003). During this event, many volunteer GIS user groups such as GISMO (Geographic Information Systems and Mapping Operations) gathered at the Emergency Mapping and Data Center at Pier 92 and provided much of the early GIS response efforts (Greene, 2002; Kawasaki and Sadohara, 2005; Curtis et al., 2006). The utilization of remote sensing imagery taken after the event, mobile equipment, and web applications used to inform the general public showed the numerous ways in which geospatial technologies can be utilized—from 
search and rescue to logistics planning and information dissemination. Further, the importance of base maps such as detailed building and land information, transportation networks, as well as support from professional GIS volunteer groups for effective response were demonstrated.

The 2004 Chuetsu earthquake in the mountainous area of Niigata, Japan caused great damages in topographical, economic, and human terms. Three weeks after the shock, the website of "Chuetsu earthquake disaster response and recovery GIS project" was opened to the public. In doing so, the relevant groups sought to make use of the Internet to collect, integrate, and disseminate information from outside the damaged area, and to support response activities from both inside and outside the disaster area (Sawada et al., 2005). In this project, imagery from remote sensing and GIS basemaps were collected and disseminated in an integrated manner. Also, an advanced data-creating trial allowed GIS volunteers living outside the damaged area to support the creation of GIS datasets using a web GIS interface.

Hurricane Katrina in 2005 demonstrated the coming age of the on-line disaster response community (Laituri and Kodrich, 2008) and revealed the importance of publicly available satellite images and other geographical data (Butler, 2006). The failure of FEMA (Federal Emergency Management Agency of the United States) in its response led a large number of individuals to bypass governmental agencies and respond by establishing donation sites, message boards, and maps of emergency aid sites. Geospatial information was also quickly utilized, after Google Maps and Google Earth updated satellite imagery of the affected area. This more accurately showed the scope of the disaster (Google, 2006).

The spontaneous disaster response-support after Hurricane Katrina opened up participation in disaster 
relief, response, and support to a much broader population. Coupled Internet and mobile applications supported the response of professional geospatial group from governmental agencies, relief response organizations, and GIS vendors (National Research Council, 2007). Private individuals and organizations used the Internet and mobile equipment to collect disaster-related information and disseminate it through websites, wikis, and blogs. These events reinforce the idea that emergency management is not a specialized activity to be performed by selected professional groups. Far from it, it is better understood as a community activity that must link local priorities with their national-level counterparts (Laituri and Kodrich, 2008).

These developments spread in the past years, and have led to the establishment of various network-based disaster response communities and the technological development of open source and web-based mapping platforms.

\section{Harvard University's geospatial portal project}

Devastating earthquakes occurred in Sichuan, China in 2008, Haiti and Chile in 2010, and Japan in 2011. Recognizing that the events had tragic consequences for people in the affected areas, the Center for Geographic Analysis (CGA) at Harvard University established a portal for the collection of geospatial data and its distribution to relevant governmental agencies, researchers, and decision makers. In doing so, CGA aimed to support the quick integration and analysis of the best available information in a disaster's immediate aftermath (Figure 1). By gathering and making accessible base data related to the earthquake as well as its impact area, CGA sought to promote broader GIS analyses of the Sichuan, Haiti, Chile and Japan earthquakes. CGA's goal was to make GIS 
data, remote sensing images, and news reports both findable and freely available to all users in the short term and to support research projects over the longer term by creating a permanent information archive. The site is targeted for specialists, though - those who need more detailed information than what is available through general services such as Google Earth and who are proficient at using GIS programs and data sets.

From the moment it established the portal sites, CGA encouraged users to contribute their own information, whether that meant posting excerpts from news reports, transferring existing GIS datasets related to the earthquake region, or processing the data and posting the results of their analysis. The goal was to provide users a free publication venue. Similarly, CGA set up the portal to allow for completely open download access. The portal does not require login information to download any or all of the datasets posted on the website. In this way, CGA hoped to encourage the free flow of information to interested parties.

\section{Sichuan earthquake}

In days following the earthquake that struck Sichuan, China on May 12th 2008, there was great demand in China for information regarding damage and recovery. A portal site of the Chinese Earthquake Administration (2010), under the administration of the State Council of the People's Republic of China, released live updates on the damaged area and response activities such as disaster inspection reports, maps, and videos. Because a number of international organizations and teams conducted surveys and rescue activities, there was a large domestic and international demand for accessing geospatial data in Sichuan. Nonetheless such a website remained unavailable at that time. CGA recognized that the Chinese government was too busy with search and rescue operations to publish 
any geospatial data pertaining to the earthquake. Although geospatial data sharing may have been implemented internally among Chinese agencies, it was difficult to access such datasets from outside the nation.

At the same time, CGA realized that many individuals and organizations around the world sought to provide immediate assistance but lacked geospatial data to support their efforts. In addition, CGA noticed that while other researchers and agencies were beginning to publish information on an ad-hoc basis, no efforts existed to coordinate the information. Therefore, CGA established the China Earthquake Geospatial Research Portal (CEGRP) about two weeks after the quake. CGA aimed to connect the portal to other groups outside China in order to support disaster relief activities and research. During the first five months, CEGRP hosted 106 postings, offered 11 downloadable data sets, and aggregated hundreds of articles per day from three hourly news feeds. Currently, there are 87 registered members and 11 subscribers to the portal as an RSS feed. The average number of page views per day is between 80 and 100 , with 27,000 views since the launch of the website. There was little access from inside China, with most access coming from the USA.

\section{Haiti earthquake}

Within a few hours of the massive 7.0-magnitude earthquake, which struck the Caribbean nation of Haiti on January 12th, 2010, CGA recognized the enormous demand for information and, on the following day, designed the

Haiti Earthquake Data Portal. CGA collaborated with Talbot Brooks, Director of the Center for Interdisciplinary Geospatial Information Technology, Delta State University, and made available a large amount of Haiti-related information. Brooks was one of the event's first responders; with members of the Geospatial Information 
Technology Association (GITA), he created basemaps for the portal within several hours after the earthquake.

Brooks's maps made use of Military Grid Referencing System (MGRS) to help responders in the field determine their position. Brooks overlaid these maps with the MGRS grids (100 meter square cells) and then compiled them into atlas books, which, accompanied by a printable scale for measuring distance, were made available for downloading as letter-sized PDF files.

The Haiti Earthquake Data Portal was launched and already publishing GIS layers within 48 hours of the event. During the first weekend following the quake, CGA staff used their large-scale plotter to print out a series of post-quake basemaps created from a high-resolution, cloudless satellite image taken the day after the earthquake. The basemaps were printed in a series of long strips (approximately 40 inches $\times 80$ inches) and when placed side-by-side provided a large-scale view of Port Au Prince. The sets of maps were rolled up into a tube for transport to Haiti by the Boston University's team, where they were quickly put to use at cabinet level emergency planning meetings at Haiti's acting Ministry of the Interior (Figure 2). This unexpected collaboration resulted from the quick deployment of the Earthquake Portal website, and was followed by other requests for data and participation from other agencies, such as the U.S. Department of Health and Human Services.

When an earthquake struck Chile on February 27th, 2010, CGA took the process further, creating a new portal for Chile in just a few hours using the Haiti portal as a template. However, Chile's situation was very different from Haiti. In Haiti's case, the government largely collapsed. As such, a huge response was required to fill the administrational void. Moreover, access to the damaged area of the Haiti island was difficult because Haiti is a small and remote country, and because some of the road network was shut down. Even some of the most basic 
informational needs such as detailed roadmaps and locations of critical assets were not available (Zook et al,. 2010).

By contrast, the Chilean government survived the earthquake intact, and their national geospatial data portal was still online after the event (Gobierno de Chile Ministerio de Planificacion, 2010). In addition, several non-governmental geospatial portals were serving data related to the Chile earthquake, unlike the situation in China in the aftermath of the Sichuan Earthquake of 2008. Of the three data portals, for Sichuan, Haiti and Chile, the Haiti portal has gotten by far the most attention and use.

Japan earthquake and Tsunami

Following the devastating event in Japan on March 11th, a designated portal was set up and running by noon on March 12th. At the same time, an email was sent out requesting data for the portal. During the first weekend several dozen resources were available, and nearly 100 emails were received offering or requesting various kinds of data (Figure 3). By Mar 18th, the site was getting more than 20,000 hits per day. One month after the quake, there were still 6,000 hits per day. The CGA also posted georeferenced topographic maps held by libraries in the US at 1:25,000 scale for the worst hit coastal towns (such as Kessanuma, Natori, etc), and at the same time requested permission to post them from Geospatial Information Authority of Japan. After about 10 days, we received official permission to post the topographic maps for the disaster region. At that time these maps were already being made available as part of the high-bandwidth server set up by Telescience (Schmidt, 2011).

Instead of getting complaint about copyright infringement, we got an official letter from USGS thanking us for the fast response, at the request of the Japanese authorities. The response and use case of the Japan portal has 
been different from the previous portals, and is still unfolding as we write this manuscript.

\section{Toward a sea change in disaster relief}

For the most part, it is generally assumed that governments or other relief entities such as the United Nations are the primary actors in disaster response and relief, with NGOs playing a secondary role. Geospatial technological development, however, has led to a sea change in disaster relief-support. Accordingly, perceptions will no doubt change with a more vigorous use of these technologies. Public interest and demand for geospatial information in disaster response-support has been rapidly increasing. Opportunities for volunteers to assist in disaster response via mapping and spatial analysis has significantly grown in size and scope And it is safe to assume that these trends will continue in the near future. This section describes how development of web-based geospatial technologies has affected the public's awareness of and involvement in a wide range of disaster relief measures.

\section{Availability of aerial and satellite imagery from the private sector}

The tendency among both space agencies and institutes and commercial companies to provide high-resolution (high-res) satellite imagery during disasters to the public for free has increased in recent years. Moreover, the observation frequency of sensors and satellites is increasing year by year, ensuring a growing range of available high-res images. This has provided a boom to disaster response. Within five days of the earthquake in Haiti, high-res satellite images from more than 15 organizations in eight countries were made freely accessible at the websites of the International Charter, and UN-SPIDER (See Table 1 for the list of remote sensing imagery used for 
the Haiti earthquake). In Haiti, more than half of the satellite data providers were commercial companies from various countries such as DigitalGlobe and GeoEye from the United States, RapidEye from Germany, and SpotImage from France. Some organizations such as DigitalGlobe and NIED (National Research Institute for Earth Science and Disaster Prevention) and JAXA (Japan Aerospace Exploration Agency), distributed imagery using their WMS (Web Map Service) server, which enabled users to obtain and use this geospatial datasets, including the ability to deploy them in their own web mapping applications and mash-ups.

The resolution of satellite images and aerial photographs has greatly improved over the past decade, making it even possible to identify damaged areas or blocked roads. After the Kashimir earthquake, high-resolution images created controversy in India and Pakistan due to concerns that they would compromise national security in Kashmir and other sensitive areas (Butler, 2005a; 2005b). While governments may see it as a security risk, the use of high-res satellite imagery is absolutely imperative for a comprehensive response to disasters. Following the Haiti quake, many high-res satellite images were made available and used to create features on OpenStreetMap, a free and open mapmaking project. In this case, volunteers viewed the imagery within the webmap mashups (such as the Haiti CrisisMap), then logged in with editing privileges to trace new features over the imagery or to add textual annotations in the same mashup application (OpenStreetMap, 2010; Zook et al., 2010). Table 1 shows which satellite images were used for editing OpenStreetMap.

\section{The new geospatial response-supporters}

The largest change in awareness of geospatial response-support has been the increase in Internet-based 
participation (Mills et al., 2009; Underwood, 2010). This includes individuals and organizations, professionals and amateurs, and people from both inside and outside the damaged area. Traditionally, government agencies tend to depend on internal information for decision-making in response and relief efforts, but now governments are accepting external datasets created by private individuals from outside the damaged area. OpenStreetMap data was broadly used by multiple agencies and NGOs on the ground in Haiti; in fact, voluntarily created geospatial information played a critical role in emergency response. This is especially true for volunteer labor. Crowd-sourced mapping allows aid agencies to focus their limited resources on other needs that cannot be easily met via distributed volunteer workers (Zook et al., 2010). This has led to the development of a divisional cooperation between those inside and outside the damaged area, individuals and organizations, and experts and amateurs, and has changed the available dataset types and geospatial response-supporters (as shown in Figure 4).

In many traditional disaster responses, prepared "GIS basemaps" (mainly used for daily work) such as buildings, land-use, critical infrastructure, and transportation network formed the core data source for emergency response-support. Professional response teams in charge of the entire geospatial operation overlaid these maps with the actual "damage information on the ground" collected through patrols, calls from citizens, or "remote sensing imagery" taken after the event (Figure 4). The teams generally consist of a "GIS specialist" for editing vector datasets and analyzing and producing maps for supporting decision-making; a "remote sensing specialist" for georeferencing and processing satellite and aerial imagery; a "database specialist"; a "project coordinator"; a "field data collector" who collects damage information and response progress on the ground using hand-set equipment with GPS; and a "web specialist" for setting up a web mapping server and creating web applications. They are 
primarily composed and managed by governmental agencies, relief response organizations, GIS software venders, and organized volunteer groups such as the above-mentioned GISMO in New York City, and mainly work at a centralized emergency operation center on-the-ground.

But the emergence of new technologies has led to a broader involvement of the general public in response support activities via the Internet. This has resulted in the emergence of a new style of disaster response-support-a networked disaster response community-that complements the traditional professional response team (as shown in the gray zone in Figure 4). As described above, these communities are comprised of formal and informal networks of people collecting, processing, and delivering information where it is needed.

The response to the Haiti earthquake provides a model for how this networked disaster response community works. Actual damage information on the ground was disseminated by the ad hoc citizen groups, local victims of the event and their families, and computer-based disaster response volunteers and supporters who collected and disseminated data in the form of text, blogs, video, pictures and maps. "Field data collectors" provided actual "damage information on the ground" through their mobile phones using Short Message Services (SMS) or GPS cell phones with cameras. For example, the Ushahidi project disseminated victim's reports as mapped information about the suffering families, damaged housing and needs for food sent via SMS from mobile phone. Such live information reportage included items such as children trapped in a collapsed school screaming for help, an 80-year-old woman with a crushed leg who needed evacuation, the location of a drum of water-purifying solution (Smith, 2010). These real-time updates on where help was most urgently needed or available -- originating as a wave of 20,000 text messages and then mapped as 3,500 incidents -- helped to save 
lives and get crucial aid to thousands of Haitians in the weeks after the quake (Provencher, 2010; Smith, 2010).

OpenStreetMap has played an important role in the networked disaster response community’s activities in Haiti. OpenStreetMap is a project to create free "peer-production geospatial data" such as road and railway networks available for use by anyone through the web. Thousands of volunteers from outside the country joined the project to create and edit maps on a wiki-like environment. Within a few days of the Haiti earthquake, the OpenStreetMap community began aiding response teams by tracing Yahoo imagery and other data sources and creating various datasets. These datasets included critical information for the responders such as roads, railways, waterways, place names for towns, and buildings including damage assessment information. Extracts of these frequently updated datasets for Haiti were made downloadable in OpenStreetMap as source files, Garmin GMAPSUPP.IMG files, and Esri shapefiles. The details of this activity are described by Zook et al. (2010).

The "public domain shared data" site GeoCommons also promoted geospatial data sharing on the web. This site allows for the upload, organization, and sharing of geospatial data, and has simple search tools that help users find data quickly. It also has functions for visual analytics through maps that require no prior training or experience with traditional mapping tools. At GeoCommons, new contents are uploaded or downloaded in KML, CSV or shapefile formats. GeoCommons is a powerful platform for data management and sharing on two levels. It has both raw data sharing function for researchers and professionals, and provides visualization and analytical tools for the general public. Crowd-sourcing is not limited to amateurs, and the GeoCommons project illustrates how institutions can crowd-source their internal data to facilitate better data sharing and collaboration. 


\section{Web-based geospatial technologies and changes in disaster response support}

“The year 2005,” D. Butler correctly identifies, “was a watershed for GIS on the Internet” (Butler, 2006). And there have been many major technological developments since then (Goodchild, 2010), a number of which are described below. This transformation of web-based geospatial technology has fundamentally changed the ways in which groups can respond to disasters. It has linked on-site responders with off-site public interest in ways that were unavailable during the World Trade Center attacks. Although these technological changes have picked up pace in recent years, the Haiti earthquake in fact represents the first disaster in which open-source, online platforms are being heavily utilized (Forrest, 2010). This section describes three incremental stages of web-based geospatial technological development, namely "web mapping and geospatial data browsing," "web-based data exchange and development," and "mash-up live editing on the web." The timeline of this technological development and disaster history and the total image of the impact of web-base geospatial technological changes on disaster response effort, are shown in Figure 5.

\section{Web mapping and geospatial data browsing}

Google Maps and Google Earth, developed by Keyhole and released in 2005, have played a defining role in increasing public awareness of geospatial data (Butler, 2006; Yang and Raskin, 2009). These web services, along with others like Microsoft Bing Maps (also known as Windows Live Maps and Live Search Maps), allow users to browse geospatial data through web mapping without installing conventional GIS software. They provide global datasets such as jurisdictional boundaries, settlement blocks, road networks, and major facilities as well as high-res 
land-cover satellite imagery in a seamless manner. Users can easily activate and deactive maps of interest, zoom in and out, and visualize spatial relationships, patterns, and trends through an Internet browser environment. Access to this global geospatial data is widely available to the general public, even to those who have never even touched GIS software. And through these programs, people now have access to high-res imagery via satellites over much of the surface of the earth.

\section{Web-based data exchange and development}

The second stage of technological development featured the growth of web-based geodata exchange formats. Keyhole Markup Language (KML), an XML language focused on geographic visualization including annotated maps and images, represents one such format. Its compressed file format, a .kmz extension, enables users to create their own geospatial datasets without using desktop GIS software. This format makes possible the creation of original geodata, the display of such data on an existing geospatial platform such as Google Earth or Google Maps, and the exchange of geodata through the Internet. The role of KML as a standard exchange format of geospatial data is expanding, to the extent that the Open Geospatial Consortium (OGC) adopted KML Version 2.2 as its implementation standard (OGC, 2010). The Web Map Service Interface Standard (WMS), a simple HTTP interface for requesting geo-registered map images from one or more distributed geospatial datasets, is another important tool of web-based data exchange. This interface was developed and first published by the OGC in 1999.

Google My Maps, released in April 2007, also has served as a platform for sharing geodata, one that does not require either the installation of GIS software or the use of a high-end expensive web server. This program 
allows users to create their own custom maps by adding place mark in any location on a map, drawing lines and adding text, picture or video. These custom maps can be shared with other users and displayed on Google Map or Google Earth.

\section{Mash-up live editing on the Web}

Creating new surfaces with web applications constitutes the third phase of geospatial technological development.

Web mapping application programming interfaces (API) such as Google Maps APIs, initially released in June 2005,

and the ESRI ArcGIS Web Mapping APIs, released in July 2009, provide software development kits (SDK) that enable developers to embed web mapping functions in a web application. This development of web mapping APIs enables thousands of individuals to create their own mapping site from multiple sources under the appearance of a single web service to end users. Such services combine satellite imagery with maps and geospatial data, provide local information by requesting maps, and provide controls and other functions with programming. This mash-up takes advantage of the best online resources from multiple sources. For example, the Scipionus map after Hurricane Katrina provided information on the status of specific locations affected by the storm and its aftermath for people affected by the disaster. It used Google Maps with other data, creating a mash-up using Google Maps API (Laituri and Kodrich, 2008; Zook et al., 2010). Creating mash-ups by seamlessly combining datasets from other sources does not necessarily require substantial geospatial skills and GIS expertise, thus making it possible for the general public with basic programming skills to volunteer relevant information and to upload their own applications on the web. 


\section{Lessons learned and thoughts for the future}

\section{The power of crowd-sourcing}

The responses to the Sichuan and Haiti earthquakes suffered from a lack of coordination among organizations and interested parties. The desire to foster greater coordination among responders led the Center for Geographic Analysis (CGA) to establish a geospatial portal, and through this experience CGA found that timing was critical in developing its portal. The sooner the portal starts, the more connections to the wider community would occur. Furthermore, CGA learned that the data had to be portable for users to acquire and at the same time easy to browse online, and all of the content had to be freely available to everyone.

Historically, both data creation and mapping in support of disaster response required professionals versed in GIS who also had access to a broad set of data for base mapping (Radke et al., 2000; Curtis et al., 2006). However, advanced GIS skills are no longer required to contribute meaningful spatial data for disaster response-support. Oftentimes, GIS information that is needed for immediate emergency response is inherently simple, merely requiring reliable and adequate data. Geographic information need only be good enough to assist recovery workers using the maps, meaning that crowd-sourced information is likely to be just as helpful as that produced by more centralized means. Given the need in disaster response for reliable maps the model of peer-produced mapping provides a number of new avenues for producing and accessing spatial data, besides the traditional top-down GIS provision models.

Perhaps the greatest benefit to this form of distributed mapping is in the greater quantity of geodata that 
can be produced and published in a shorter period of time. This allows scarce technical and other resources to be

diverted to where they are needed most, including search and rescue, waste and body removal, food distribution, temporary housing, and community planning. Crowd-sourcing is about more than just volunteers and amateurs, however. It is about creating fluidity in data sharing and collaboration by breaking down barriers to technology and participation through the web, open standards, and simplified interfaces.

Rapid response and reliable data, however, are only part of the picture of crowd sourcing. We must also consider how the crowd-sourced information was processed and vetted, then fed into the live mash-ups. After all, inaccurate or carelessly uploaded information could very well hinder relief and rescue operations. So how can groups ensure both rapid mapping and reliable data? The Ushahadi team is instructive in this vein. They set up a system of SMS and phone banks where volunteers received information in real time. Other teams of volunteers checked and evaluated the data before posting them onto the website (Provencher, 2010; Smith, 2010). This was a flexible means of dealing with the problems of crowd sourcing and ensuring the accuracy of uploaded data. Efficient management of crowd-sourcing operations, then, should be seen as the key element that determines the success or failure of this new data creation endeavor.

\section{Need disaster response plans that utilize the networked disaster response community}

Disaster communications used to be strictly top-down, hierarchical and linear, where public officials and experts were the ones who pushed the information out (Mills et al., 2009), but experience has shown that this approach to data sharing in disaster management is not entirely effective (Radke et al., 2000). 
Except for special cases such as Haiti, where the central government collapsed, a governmental agency or

relief response organization should play a centralized role for coordinating general disaster response. The scale and complexity of problems presented by recent disasters highlight the need for greater collaboration; no stakeholder has the capability to tackle them alone (Pezzoli et al., 2007). Therefore, government and relief response organizations have to understand how to harvest energy from the new technologies and the emergence of crowd-sourced responders, for instance in making inventories of damages and identifying where help is needed. Crowd-sourced disaster response demonstrated the power and speed with which people could disseminate information. It is important to have an established plan that includes this crowd-sourced movement in order to maximize the use of volunteers in the geospatial response and direct resources from all over the world (Curtis et al., 2006; Zook et al., 2010). In addition, collaboration and coordination between governmental agencies, relief organizations, and commercial companies remain problematic due to conflicting missions, data security issues, and inadequate funding of emergency response technologies (National Research Council, 2007; Laituri and Kodrich, 2008). Understanding the capabilities of the crowd-sourced disaster responders offers an opportunity for integration of local perspectives and skills to augment agencies stretched to capacity by a devastating disaster and inadequate funding (Laituri and Kodrich, 2008).

Some effort needs to go into coordinating the crowd-sourced data streams (which can be collected and processed anywhere) with disseminating live information to the people on the ground (which can only be done on site and which usually has no power, no internet access, etc.). From the authors' conversations with US Department of Health and Human Services staff and responder agencies, one of the biggest issues remains the ability to feed 
updated info about the situation on the ground directly into the hands of the on-site responders. For example, Ushahidi did a brilliant work of getting OpenStreetMap coverage digitized for Port Au Prince and added much useful information about road blockages and food and water distribution points, to name a few. However, those webmaps remained unavailable to the responders on the ground. The Ushahidi group were bereft of a clearinghouse at ground zero - like a phone bank or a bulletin board - that could keep track of live updates and indicate which hospitals had open beds and what kind of surgeons or equipment were on site. Responders in a disaster zone require the most up-to-date information. For instance, when dealing with injured persons, responders need to hasten them to the closest facility that has the staff and equipment necessary for treatment. The lack of a centralized clearinghouse for updated information limits the effectiveness of responders. The authors anticipate that the next wave of geospatial technology development will be on the mobile platforms, which enables most cell phones to enter and receive locational information from anywhere, feeding real time field data to the web-based systems, and in term accessing the webmaps for latest updates.

There are discussions as to whether governmental agencies should lead this role for information centralization or other entities in the distributed network should take this role (Rajabifard, 2006). Governmental agencies tend to hesitate in sharing data to external entities due to its organizational characteristics (Tombs, 2005; Harvey and Tulloch, 2006; Elwood, 2008). Nonetheless, effective disaster response necessitates a removal of barriers for collaboration with crowd-sourcing responders. Even though a government agency needs to limit data sharing to some degree, they also have to maximize their limited sources by integrating external resources. Data sharing on disaster sites has to remain highly available to the public. 


\section{Rapid building inspection}

In the Haiti earthquake, many volunteer responders contributed to assessing building, road, and bridge damages by checking the visibility of houses from high-res satellite imagery. There is no doubt that this was helpful for responders on the ground in conducting search and rescue operations, distributing resources, and establishing emergency operation sites. However, ground evaluation of this useful assessment from 2D high-res imagery (even if it is very high resolution) is required to establish a guideline on the reliability of satellite imagery. For example, it is necessary to develop a method for assessing infrastructure of houses, roads, and bridges by combining high-res imagery taken from space with pictures taken by victims or responders on the ground. By establishing guidelines for taking pictures (shooting angle, direction, location) using hand-held equipment and sending them to building inspectors in remote places, relief agencies can conduct more detailed and reliable assessments of damaged areas.

\section{Quick response vs. long-term strategies of geospatial database development}

Zook et al. (2010) suggested that detailed databases that used to take years to create now had to be accomplished in a matter of days using collaborative user environments such as OpenStreetMap. It is true that collaborative user environments are useful for an emergency response-support in the wake of a disaster. At the same time, however, we wonder whether these datasets can be utilized in long-term recovery planning and rebuild. Feature datasets created through OpenStreetMap are in a simple GIS format. This is not a well-structured spatial data model with modeling and analytical capabilities such as ESRI's geodatabase data model. It is a good opportunity to create 
geospatial datasets after a disaster, especially in developing countries. A new comprehensive geospatial database could be useful not only in emergency response-support but also in long-term national or regional planning, including addressing other issues such as climate change adaptation and global warming mitigation. The development of multifunctional databases allows a variety of applications such as revenue collection, natural resource protection, land-use planning, and infrastructure planning as well as disaster planning (Montoya, 2003). Long-term strategies for building and utilizing multifunctional geospatial databases should be considered so that we do not waste the effort to create a variety of datasets which was intensively devoted to disaster response through humanitarian crowd-sourcing.

\section{Conclusion}

This paper examined how disaster response and relief efforts have been changing along with recent geospatial technological development. It argued that conventional GIS disaster responses by governmental agencies and relief response organizations and the means for geospatial data sharing have been transformed into a more dynamic, more transparent, and more decentralized form, one that incorporates a much wider range of participation. Web mapping and geospatial data browsing with high-res satellite images and advanced data exchange have combined professional expertise and public involvement in ways unimaginable even a decade ago. In addition to the conventional governmental approach, open source and voluntary activities have expanded to such an extent that effective disaster relief today relies on both professional organizations and enthusiastic volunteers. Coordination and collaboration among these groups is critical for a comprehensive and effective response to disasters. The 
combination of the professionalism of relief agencies and the enthusiasm of volunteers to contribute via crowd-source technologies will change the way disasters are handled. In this vein, however, it is critical that those with professional expertise in handling disasters understand the trend in geospatial technologies.

This paper, however, merely represents a first step outlining the ways in which geospatial technologies have been used for disaster relief and response. Looking to the future, this topic would benefit from broader research in a variety of topical fields, from continued studies of technological developments to those of public health, civil engineering, economics, and studies of displaced persons and remediation efforts. Geospatial technologies will only expand in size and scope in the coming years. As such, policy studies will need to provide continued research on and recommendations for effective use of this game changing technology. 
Figure 1 The Haiti Earthquake Data Portal top page (Source: Authors)

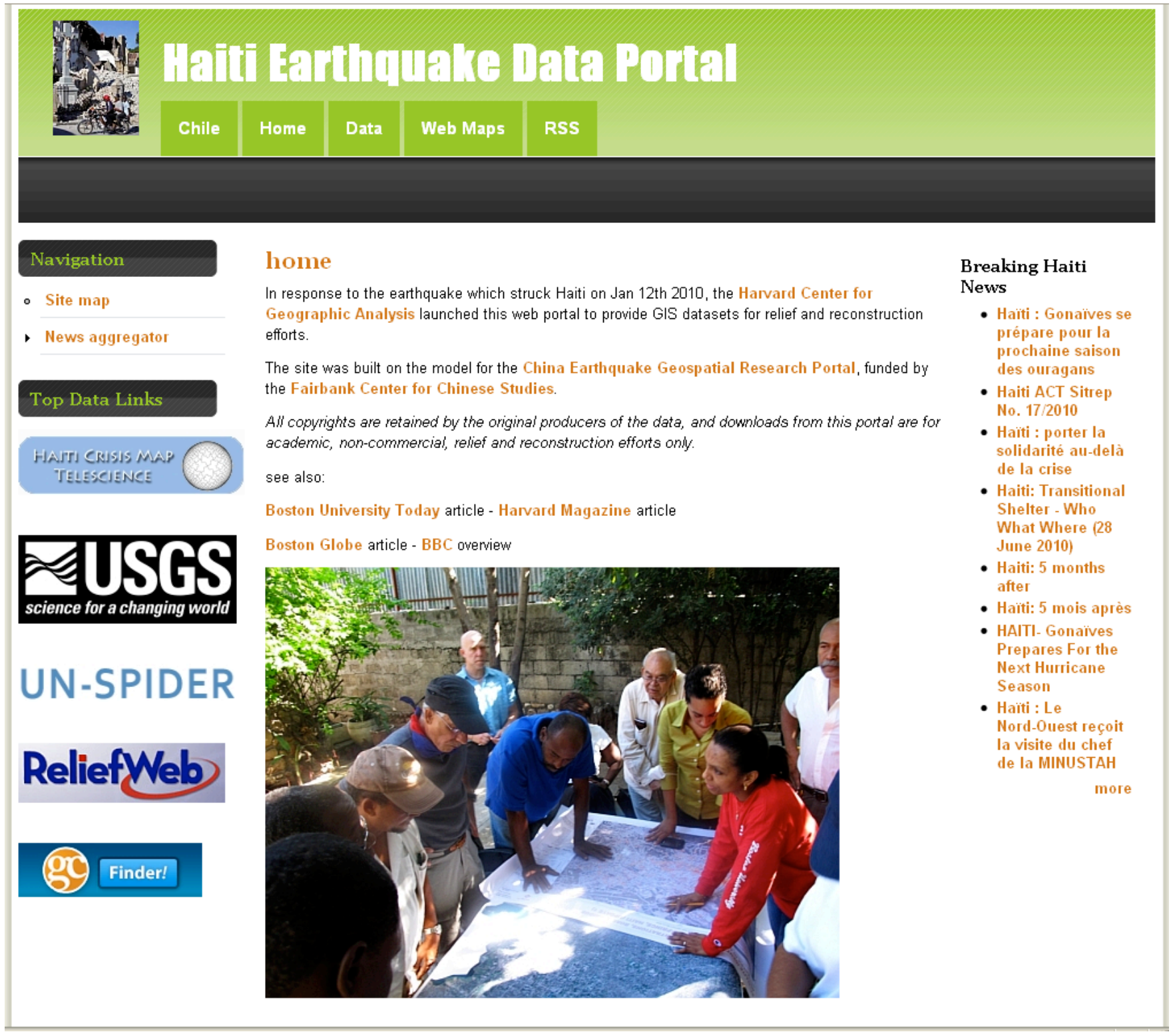


Figure 2 Discussions at the pro tem Executive Office in Port Au Prince with Haitian President René Préval (Source: Authors)

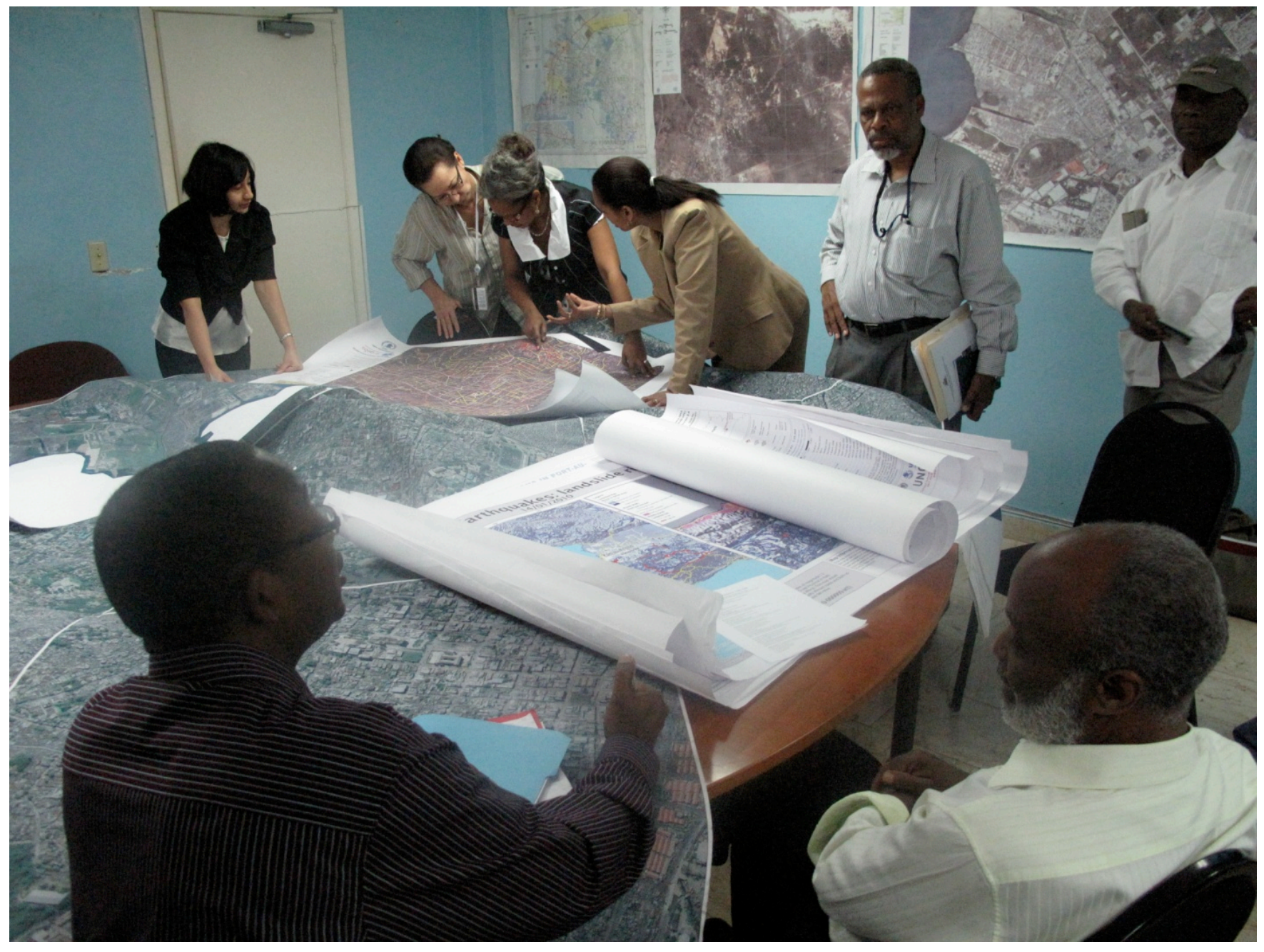


Figure 3 The Japan Data Portal downloadable GIS data page (Source: Authors)

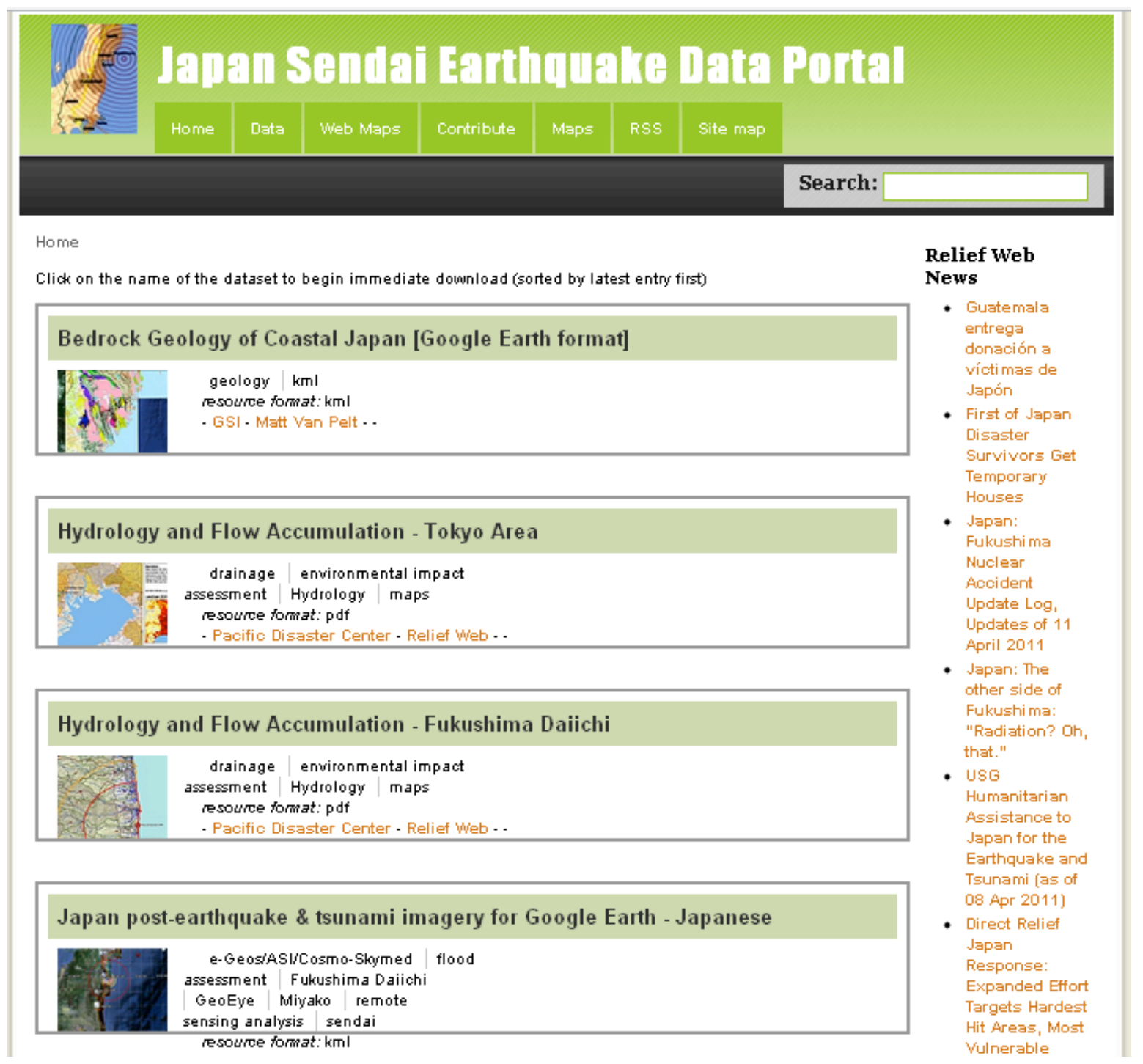


Figure 4 Change in available dataset type and geospatial response-supporter (Source: Authors)

Available dataset type

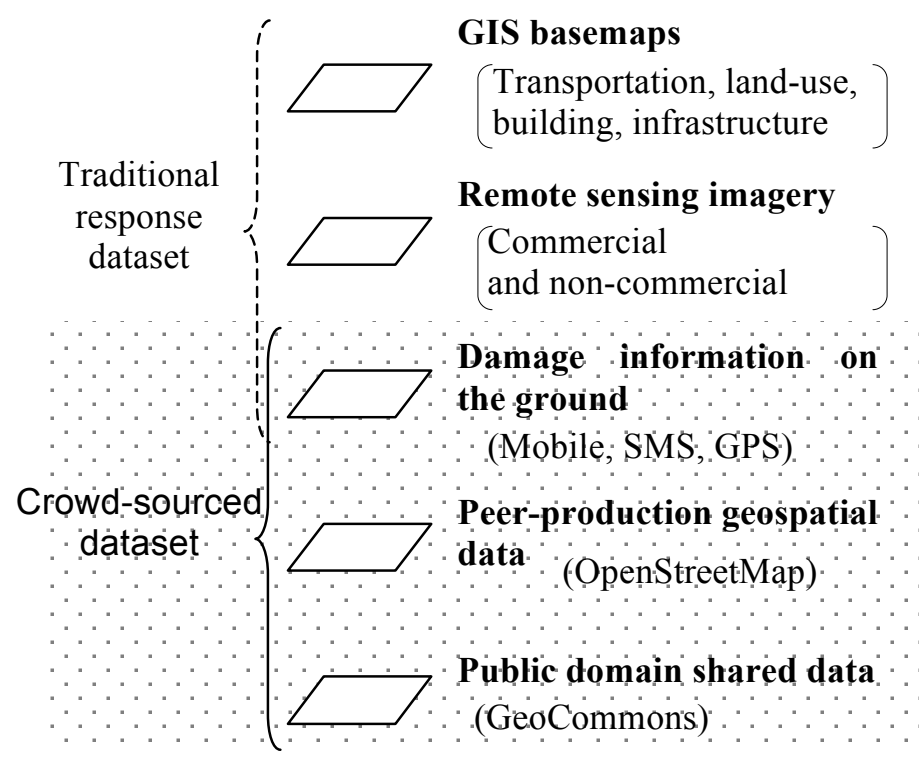

\section{Geospatial response-supporter}

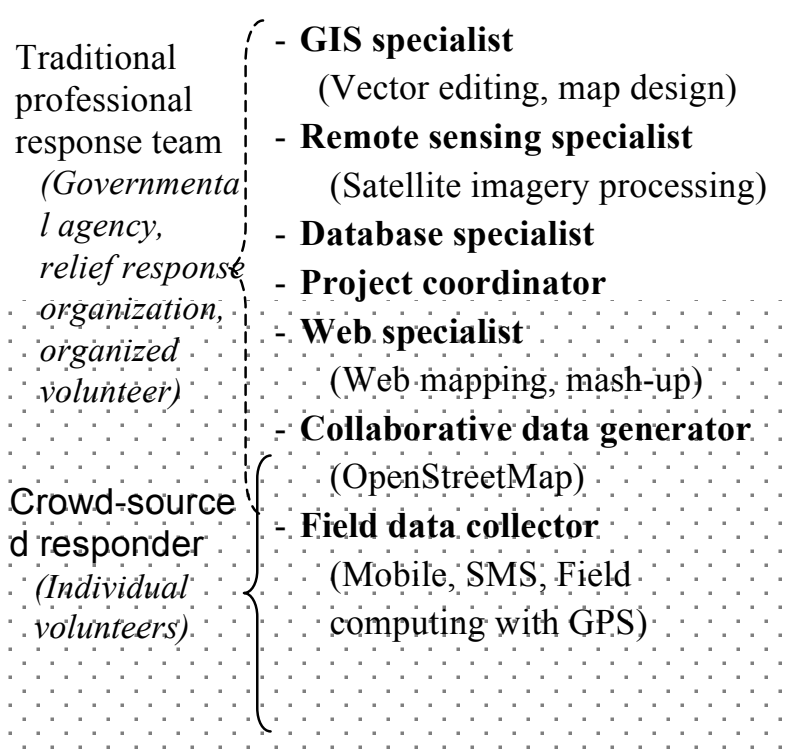


Figure 5 An overview of recent devastating disasters and the impact of changes in geospatial technology on disaster relief effort (Source: Authors)

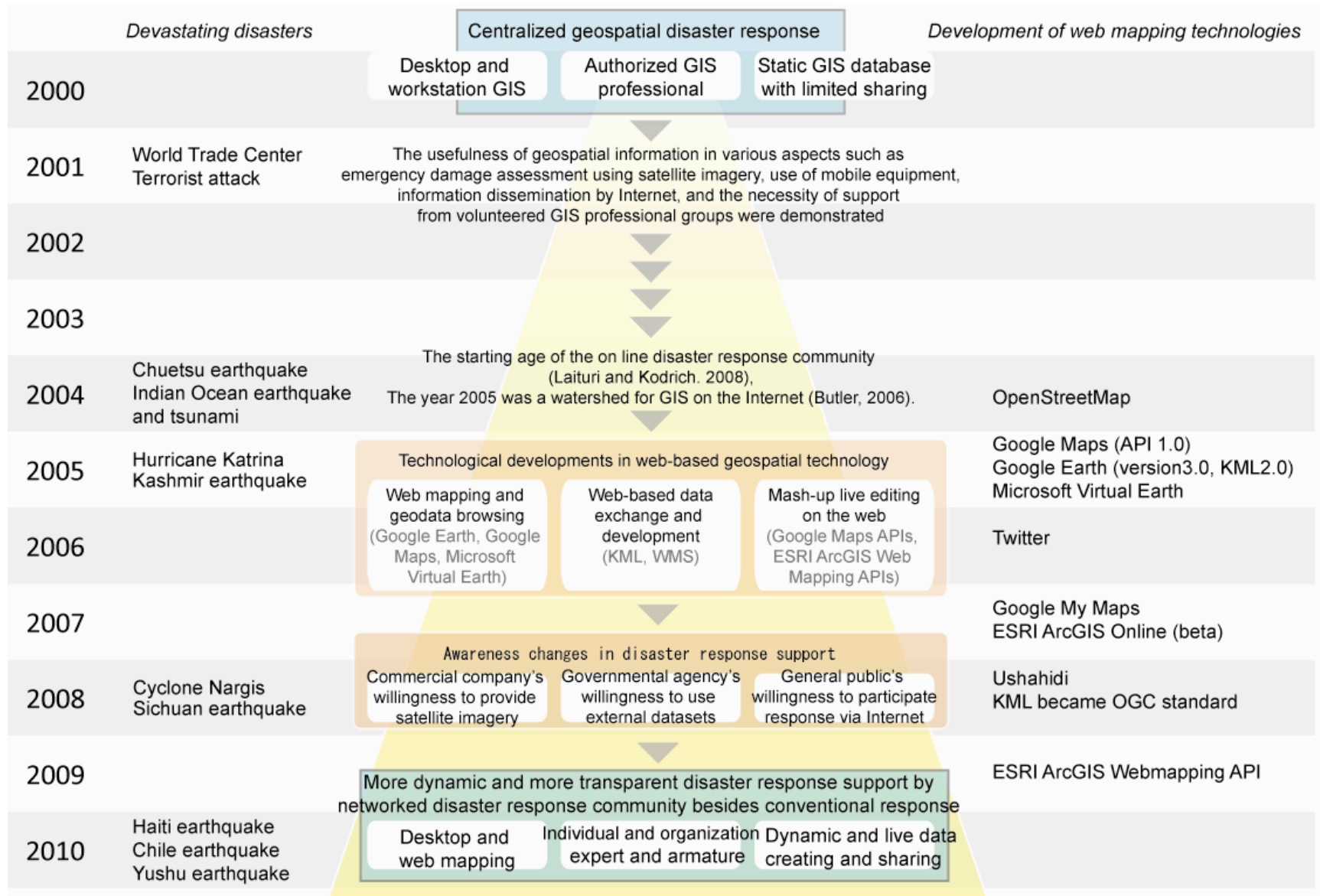


Table 1 Remote sensing imagery used during the Haiti earthquake in 2010

\begin{tabular}{|c|c|c|c|}
\hline Data provider & Satellite & $\begin{array}{l}\text { First dates } \\
\text { of acquirement }\end{array}$ & $\begin{array}{l}\text { The use } \\
\text { at } \mathrm{OSM}^{1}\end{array}$ \\
\hline $\begin{array}{l}\text { NOAA (National Oceanic and } \\
\text { Atmospheric Administration), USA }\end{array}$ & $\begin{array}{c}\text { Cessna Citiation } \\
\text { II (aircraft) }\end{array}$ & $1 / 18$ & + \\
\hline \multirow[t]{2}{*}{ GeoEye, Inc., USA } & GeoEye-1 & $1 / 13$ & \multirow[t]{2}{*}{+} \\
\hline & IKONOS & $1 / 17$ & \\
\hline \multirow[t]{3}{*}{ DigitalGlobe, Inc., USA } & QuickBird & $1 / 15$ & \multirow[t]{3}{*}{+} \\
\hline & WorldView-1 & $1 / 14$ & \\
\hline & WorldView-2 & $1 / 15$ & \\
\hline $\begin{array}{l}\text { EROS (Earth Resources Observation } \\
\text { Satellite) Corp., US and Israel }\end{array}$ & EROS B & $1 / 17$ & + \\
\hline $\begin{array}{l}\text { CNES (Centre National d'Etudes } \\
\text { Spatiales) and Spot Image, France }\end{array}$ & Spot 5 & $1 / 14$ & + \\
\hline SpotImage & Formosat-2 & $1 / 13$ & \\
\hline \multirow{4}{*}{$\begin{array}{l}\text { NIED (National Research Institute for } \\
\text { Earth Science and Disaster } \\
\text { Prevention), and JAXA (Japan } \\
\text { Aerospace Exploration Agency), } \\
\text { Japan }\end{array}$} & \multirow[t]{4}{*}{ ALOS } & 1/23 (Pan-sharpened) & \multirow[t]{4}{*}{+} \\
\hline & & 1/23 (PRISM) & \\
\hline & & 1/13 (AVNIR-2) & \\
\hline & & 1/16 (PALSAR) & \\
\hline e-GEOS S.p.A., Italy & $\begin{array}{c}\text { cosmo-SkyMe } \\
\mathrm{d}\end{array}$ & $1 / 15$ & \\
\hline $\begin{array}{l}\text { MacDonald, Dettwiler } \\
\text { and Associates Ltd., Canada }\end{array}$ & Radarsat-2 & $1 / 14$ & \\
\hline China & $\mathrm{HJ}-1-\mathrm{A} / \mathrm{B}$ & $1 / 14$ & \\
\hline RapidEye AG, Germany & RapidEye & $1 / 13$ & \\
\hline Infoterra $\mathrm{GmbH}$, Germany & TerraSAR-X & $1 / 14$ & \\
\hline NASA, USA & \begin{tabular}{|c|} 
Earth Observing \\
One (EO-1)
\end{tabular} & $1 / 15$ & \\
\hline
\end{tabular}




\section{Endnotes}

${ }^{1}$ Source: (WikiProject Haiti, 2010); Summarized by authors (date as of April 2010)

\section{Reference}

Butler, D. (2005a) 'Quake Aid Hampered by Ban on Web Shots'. Nature. 437. pp. 1072-73.

Butler, D. (2005b) ‘UN Opens Access to Earthquake Shots’. Nature. DOI:10.1038/news051017-12.

Butler, D. (2006) 'The Web-Wide World'. Nature. 439. pp. 776-78.

Butler, D. (2007) 'Data Sharing: the Next Generation'. Nature. 446. pp. 10-11.

Chinese Earthquake Administration (2010) Chinese Earthquake Administration Website. http://www.cea.gov.cn.

Cova, T.J. (1999) 'GIS in Emergency Management'. In P.A. Longley, M.F. Goodchild, D.J. Maguire and D.W.

Rhind (eds) Geographic Information Systems: Principles, Techniques, Applications, and Management. New

York: John Wiley \& Sons. pp. 845-58.

Curtis, A., J.W. Mills, J.K. Blackburn and J.C. Pine (2006) 'Hurricane Katrina: GIS Response for a Major Metropolitan Area'. Quick Response Report. 180. pp. 1-6.

Cutter, S.L. (2003) 'GI Science, Disaster, and Emergency Management'. Transactions in GIS. 7(4). pp. 439-45.

Elwood, S. (2008) 'Grassroots Groups as Stakeholders in Spatial Data Infrastructures: Challenges and Opportunities for Local Data Development and Sharing'. International Journal of Geographical Information Science. 22(1). pp. 71-90.

Forrest, B. (2010) 'Technology Saves Lives In Haiti'. Forbes.com. 
http://www.forbes.com/2010/02/01/text-messages-maps-technology-breakthroughs-haiti.html

Gobierno de Chile Ministerio de Planificacion (2010) InfoPais. http://www.infopais.cl.

Goodchild, M.F. (2010) 'Twenty years of progress: GIScience in 2010'. Journal of Spatial Information Science. 1.

pp. 3-20.

Google (2006) ‘Google Earth and Katrina Help'. The Official Google Blog.

http://googleblog.blogspot.com/2006/07/google-earth-and-katrina-help.html.

Greene, R.W. (2002) Confronting Catastrophe: A GIS Handbook. Redlands: ESRI Press.

Harvey, F. and D. Tulloch (2006) 'Local-government Data Sharing: Evaluating the Foundations of Spatial Data Infrastructures'. International Journal of Geographical Information Science. 20(7). pp. 743-68.

Householder, E.J. (1999) 'Lifesaving Choices: Developing a Comprehensive Critical Facility Geo-spatial Database for Regional Emergency Management'. Proceedings of the 19th ESRI International User Conference. 445.

Huych, C.K. and B.J. Adams (2002) Emergency Response in the Wake of the World Trade Center Attack: The Remote Sensing Perspective, Engineering and Organizational Issues Related to the World Trade Center Terrorist Attack. MCEER Special Report Series. New York: MCEER.

ISDR (2009) Global Assessment Report on Disaster Risk Reduction. Geneva: UNISDR.

Johnson, G.O. (1992) ‘GIS Application in Emergency Management’. URISA Journal. 4. pp. 66-72.

Katayama, T. (1991) Earthquake Damage Assessment by Considering Local Characteristics. Tokyo: Research and Survey on Earthquake Insurance.

Kawasaki, A. and S. Sadohara (2005) 'Investigation of the Utilization of GIS in Emergency Response to the 2001 
WTC Building Collapse Disaster No.2: Through the Interviews in New York City'. Proceedings of the Annual Conference of Institute of Social Safety Science. 16. pp. 1-4.

Laituri, M. and K. Kodrich (2008) 'On Line Disaster Response Community: People as Sensors of High Magnitude Disasters using Internet GIS'. Sensors. 8. pp. 3037-55.

Longueville, B.D. (2010) 'Community-based Geoportals: The Next Generation? Concepts and Methods for the Geospatial Web 2.0'. Computers, Environment and Urban Systems. 34. pp. 299-308.

Matsuoka, M. and F. Yamazaki (2001) Characteristics of Satellite SAR Intensity Images in Building Damage Areas due to the 1995 Hyogo-ken Nanbu Earthquake'. Journal of Architecture and Structure. 546. pp. 55-61.

Matsuoka, M., F. Yamazak and S. Midorikawa (2001) 'Characteristics of Satellite Optical Images in Areas Damaged by the 1995 Hyogo-ken Nanbu Earthquake'. Journal of Structural Mechanics and Earthquake Engineering. 668(I-54). pp. 177-85.

Meguro, K., M. Soejima, F. Yamazaki and T. Katayama (1999) 'Classification of Urban Area by Characteristics of Power Load Curve'. Information Technology Tools for Natural Disaster Risk Management- Proceedings of International Symposium. pp. 263-74.

Mills, A., R. Chen, J. Lee and H.R. Rao (2009) 'Web 2.0 Emergency Applications: How Useful can Twitter be for Emergency Response?'. Journal of Information Privacy \& Security. 5(3). pp. 3-26.

Mitsutomi, H., M. Matsuoka and F. Yamazaki (2002) 'A Study on a General Automated Detection Method of Building Damage Areas using Aerial Television Images'. Journal of Structural Mechanics and Earthquake Engineering. 710(I-60). pp. 413-25. 
Montoya, L. (2003) 'Geo-data Acquisition through Mobile GIS and Digital Video: an Urban Disaster Management Perspective'. Environmental Modelling \& Software. 18. pp. 869-76.

National Research Council (2007) Successful Response Starts with a Map: Improving Geospatial Support for Disaster Management. Washington, D.C.: The National Academies.

Nourbakhsh, I., R. Sargent, A. Wright, K. Cramer, B. McClendon and M. Jones (2006) 'Mapping Disaster Zones'. Nature. 439(7078). pp. 787-88.

OGC (2010) 'OpenGIS® Standards and Specifications'. The Open Geospatial Consortium, Inc. http://www.opengeospatial.org/standards.

OpenStreetMap (2010) 'WikiProject Haiti’. http://wiki.openstreetmap.org/wiki/WikiProject_Haiti.

Pezzoli, K., R. Tukey, H. Sarabia, I. Zalavsky, M. Miranda and W.A. Suk (2007) 'The NIES Environmental Health Sciences Data Resource Portal: Placing Advanced Technologies in Service to Vulnerable Communities'. Environmental Health Perspectives. 115(4). pp. 564-71.

Provencher, K. (2010) ‘Crowdsourcing Crisis Response'. Tufts E-News. Medford: Tufts University. http://enews.tufts.edu/stories/1621/2010/02/05/crisismappingz.

Radke, J., T. Cova, M.F. Sheridan, A. Troy, M. Lan and R. Johnson (2000) 'Application Challenges for Geographic Information Science: Implications for Research, Education, and Policy for Emergency Preparedness and Response'. URISA Journal. 12(2). pp. 15-30.

Rajabifard, A., A. Binns, I. Masser and I. Williamson (2006) 'The Role of Sub-national Government and the Private Sector in the Future Spatial Data Infrastructures'. International Journal of Geographical Information 
Science. 20(7). pp. 727-41.

Rolbein, S. (2010) 'Haiti Leaders, BU Team Share Long-Term Goals'. BU Today In the World. Boston: Boston University.

Saito, K., Y. Numata, H. Shimamura, L. Zhu, Y. Akamatsu, Y. Nakayama and S. Miyazaki (2009) 'Investigation Report on the Use of Remote Sensing Technology in Large-scale Disaster Assessment'. Seisan-kenkyu. 61(4). pp. 157-63.

Sawada, M., H. Yagi and H. Hayashi (2005) 'A Study on the Technique for Information Sharing and Presentation of Earthquake Disasters: By the Chuetsu Earthquake Restoration and Revival Support GIS Project'. Journal of Social Safety Sciences. 7. pp. 97-102.

Schmidt, C., Graham, J., and Rush, B. (2011) Japan Earthquake: GSI_1_25000_topo. http://hyperquad.telascience.org/jp_earthquake/

Smith, J.F. (2010) 'Tufts Map Steered Action amid Chaos'. The Boston Globe. http://www.boston.com/news/ world/latinamerica/articles/2010/04/05/tufts_project_delivered_aid_to_quake_victims.

Thomas, D.S.K., S.L. Cutter, M. Hodgson, M. Gutekunst and S. Jones (2002) 'Use of Spatial Data and Geographic Technologies in Response to the September 11 Terrorist Attack'. Quick Response Report. 153.

Tombs, R.B. (2005) 'Policy Review: Blocking Public Geospatial Data Access is Not Only a Homeland Security Risk'. URISA Journal. 16(2). pp. 49-51.

Underwood, S. (2010) 'Improving Disaster Management'. Communications of the ACM. 53(2). pp. 18-20.

WikiProject Haiti (2010) 'Imagery and data sources'. 
http://wiki.openstreetmap.org/wiki/WikiProject_Haiti/Imagery_and_data_sources.

Yang, C. and R. Raskin (2009) 'Introduction to Distributed Geographic Information Processing Research'. International Journal of Geographic Information Science. 23(5). pp. 553-60.

Yoshitomi, P. (2004) 'The Role of GIS in the Response to the Terrorist Attacks of September 11 in New York City'. Annuls of Disaster Prevention Research Institute, Kyoto University. 47(C). pp. 325-30.

Zook, M., M. Graham, T. Shelton and S. Gorman (2010) 'Volunteered Geographic Information and Crowdsourcing Disaster Relief: A case Study of the Haitian Earthquake'. World Medical \& Health Policy. 2(2). DOI: 10.2202/1948-4682.1069. 